\title{
FILOSOFIA E POLÍTICA DA ESPACIALIDADE: ALGUMAS CONSIDERAÇÕES*
}

\author{
DoReEn MASSEY \\ Open University \\ Milton Keynes \\ Reino Unido
}

Minha principal preocupação neste texto é com a questão de como podemos pensar o espaço/a espacialidade ${ }^{1}$ - hoje em dia, na nossa época e no contexto dos debates nos quais estamos envolvidos e dos desafios que estamos enfrentando. "Espaço" é uma daquelas coisas mais óbvias, mobilizada como termo em mil contextos diferentes, mas cujos significados potenciais são todos muito raramente explicados ou focalizados. Como Grossberg escreveu:

Freqüentemente, as características mais "óbvias" da nossa experiência-por exemplo, a distinção entre espaço e tempo - são as menos examinadas filosoficamente. (GROSSBERG, 1996: 171)

Meu interesse particular, no contexto desta semana em Heidelberg ${ }^{2}$, é explorar as conexões entre, por um lado, esta questão de como conceitualizar espaço e, por

\footnotetext{
* Artigo traduzido a partir de: Massey, D. 1999. Power-Geometries and the Politics of Space-Time (Hettner-Lecture 1998). Heidelberg: Departamento de Geografia da Universidade de Heidelberg. Tradução: Rogério Haesbaert. Agradecemos a Maurício de Almeida Abreu pela revisão e à própria autora pelos esclarecimentos em relação a alguns pontos da tradução. Cabe agradecer também ao Departamento de Geografia da Universidade de Heidelberg pela autorização desta tradução.

1. Estes termos serão usados de forma intercambiável neste artigo.

2. A autora refere-se aqui ao período em que passou em Heidelberg por ocasião da homenagem que recebeu durante a Hettner-Lecture 1998. (N. T.)
} 
outro, primeiro, como a teorização na Ciência Social é conduzida ${ }^{3}$ e, segundo, como estes dois aspectos estão relacionados com aquilo que parecem ser as mudanças significativas, hoje, na filosofia política e no pensamento político em sentido mais geral. A conexão com a teorização nas Ciências Sociais (o desafio de espacializar a teoria social) é abordada no artigo "Imagining Globalisation: PowerGeometries of Space-Time" (MASSEY, 1999).

Iniciemos, então, nosso argumento. Apresento a seguir três proposições sobre como o espaço pode ser conceitualizado 4 :

1. O espaço é um produto de inter-relações. Ele é constituído através de interações, desde a imensidão do global até o intimamente pequeno (esta é uma proposição que não representa nenhuma surpresa para aqueles que têm acompanhado a literatura anglófona recente!) ${ }^{5}$.

2. O espaço é a esfera da possibilidade da existência da multiplicidade; é a esfera na qual distintas trajetórias coexistem; é a esfera da possibilidade da existência de mais de uma voz. Sem espaço não há multiplicidade; sem multiplicidade não há espaço. Se o espaço é indiscutivelmente produto de inter-relações, então isto deve implicar na existência da pluralidade. Multiplicidade e espaço são co-constitutivos.

3. Finalmente, e precisamente porque o espaço é o produto de relações-entre, relações que são práticas materiais necessariamente embutidas que precisam ser efetivadas, ele está sempre num processo de devir, está sempre sendo feito - nunca está finalizado, nunca se encontra fechado.

Este último ponto é, provavelmente, de particular importância, pois ele implica que existem sempre - em algum momento "no tempo" - conexões ainda por serem realizadas, justaposições ainda por se transformarem em interações (ou não, pois nem todas as conexões potenciais precisam ser estabelecidas), relações que podem

\footnotetext{
3. Existem conexōes também com as ciências naturais, mas estas são mencionadas aqui apenas de forma breve (para uma exploração detalhada, ainda que preliminar, v. Massey, mimeo.)

${ }^{4}$. A primeira parte deste artigo baseia-se no artigo "Spaces of politics", publicado em Massey, Allen e Sarre, 1999.

5. Deve-se observar que eu não especifico aqui aquelas "inter-relações" como sendo especificamente "sociais". De fato, é o "espaço social" que tenho primeiro em mente neste contexto. Seria inadequado, entretanto, limitar desnecessariamente o conceito à nossa definição usual de social, significando "relacionado ao homem" (este ponto se refere à nota 3). Sobre os significados potenciais mais amplos de "social", nos quais ele pode abarcar, de forma mais geral, as interrelações, v. Adam, 1990.
} 
ou não ser efetivadas. Assim, nesta forma de imaginar as coisas, o espaço é sem dúvida um produto de relações (primeira proposição) e, por ser assim, deve ser também multiplicidade (segunda proposição). Entretanto, estas não são absolutamente relações de um sistema coerente, fechado, dentro do qual, como se diz, "tudo está (já) relacionado com tudo". Neste modo de imaginá-lo, o espaço pode não ser, nunca, aquela simultaneidade completa na qual todas as interconexões foram estabelecidas, e na qual tudo já está interligado com tudo.

$* * *$

Desse modo, o argumento aqui é o de que esta abordagem para a conceitualização do espaço/espacialidade repercute nas recentes mudanças em certas áreas no modo pelo qual a política "progressista" também pode ser imaginada. Embora fosse incorreto e também rigidamente constringente propor qualquer mapeamento biunívoco, o fato é que cada uma das três proposições acima enunciadas elucida um aspecto ligeiramente distinto desta conexão. Assim:

i. Imaginar o espaço como um produto de inter-relações (primeira proposição) está bem de acordo com a emergência em anos recentes de uma política que tenta operar através de um compromisso com o anti-essencialismo. Isto é, no lugar de um tipo de política da identidade que toma estas identidades como já e para sempre constituídas ("mulher", "homossexual"), e defende os direitos de, ou reivindica igualdade para aquelas identidades já constituídas, esta política anti-essencialista toma a constituição das próprias identidades como um dos suportes centrais do político. Mais do que aceitar e trabalhar com identidades já constituídas, esta política anti-essencialista enfatiza a construção de identidades e coisas (incluindo as denominadas subjetividades políticas e constituintes políticos). Por isso devemos ser prudentes a respeito de reivindicações de autenticidade baseadas em noções de identidade imutável. Ao contrário, ela propõe um entendimento relacional do mundo.

Esta política de inter-relações reflete, então, a primeira proposição deste artigo, a de que também o espaço é um produto de inter-relações. Sem dúvida, num sentido mais geral, eu defenderia que as identidades/entidades, as relações "entre" elas e a espacialidade que delas faz parte são todas co-constitutivas (MASSEY, 1995). Chantal Mouffe, em particular, escreveu muito criteriosamente sobre como devemos conceitualizar a construção relacional das subjetividades políticas (MOUFFE, 1993 e 1995). Para ela, a identidade e a inter-relação são constituídas conjuntamente. O que estou propondo aqui é que o espaço é necessariamente parte integrante e produto desse processo de constituição. Assim, não somente existe um paralelo entre a maneira de conceitualizar o espaço e a maneira de conceitualizar entidades/identidades (tais como sujeitos políticos), mas também o espaço é, desde o início, parcela integrante da constituição daquelas subjetividades políticas. 
ii. Além disso, imaginar o espaço como a esfera da possibilidade da existência da multiplicidade (segunda proposição) está de açordo com a maior ênfase dada recentemente pelos discursos políticos de esquerda à "diferença" e à multiplicidade. Assim, naquilo que tem sido talvez a forma mais evidente de sua manifestação, há uma crescente insistência na idéia de que a estória (story) do mundo não pode ser contada (e nem sua geografia elaborada) apenas através dos olhos do "Ocidente" (como por longo tempo foi o caso), nem do ponto de vista, por exemplo, da clássica figura (com frequiência, ironicamente, ela própria essencializada) do macho branco heterossexual. Esta perspectiva insiste no reconhecimento de que estes entendimentos (através dos olhos do Ocidente ou do homem heterossexual) são eles mesmos específicos, pontos de vista locais muito particulares e não os universais como por longo tempo eles próprios propuseram. Trata-se de uma abordagem que tem sido elaborada e defendida, sobretudo, pelas feministas e por aqueles que trabalham dentro da fundamentação dos estudos pós-coloniais.

A relação entre este aspecto de uma política mutável (e de uma forma de fazer teoria social) e a segunda proposição sobre o espaço é de natureza bastante distinta daquela vinculada à primeira proposição. Neste caso, o argumento é de que a verdadeira possibilidade de qualquer reconhecimento sério da multiplicidade e da diferença depende ele próprio de um reconhecimento da espacialidade. Com muita frequiência este reconhecimento estará implícito (algumas vezes de forma inofensiva, em outras com efeitos seriamente prejudiciais); outras vezes, particularmente quando a própria espacialidade é uma das dimensões da construção da diferença, ele será - na realidade, deve ser - explícito. Este argumento será abordado novamente mais tarde, mas a essência do caso é que para que haja multiplicidade (e, por extensão, para que haja diferença) deve existir espaço.

iii. Finalmente, imaginar o espaço sempre em um processo de devir, nunca como um sistema fechado (terceira proposição), vai de encontro a uma crescente insistência dos discursos políticos a respeito de uma genuína abertura para o futuro. É uma insistência fundada na tentativa de escapar da inexorabilidade que freqüentemente caracteriza as grandes narrativas ligadas à Modernidade. Os fundamentos do "Progresso", do "Desenvolvimento" e da "Modernização" e á sucessão de modos de produção elaborada pelo Marxismo, todos eles propõem cenários nos quais as direções gerais da história, incluindo o futuro, são conhecidas. Por mais que muita batalha seja necessária para realizá-los, ou engajar-se em lutas para atingi-los, existia sempre, não obstante, uma conviç̧ão de fundo sobre a direção em que a história estava se movendo. Hoje, muitos teóricos rejeitam tal formulação e argumentam, ao contrário, a favor de uma abertura radical do futuro, seja através de uma democracia radical (LACLAU, 1990), de noções de noma- 
dismo (DELEUZE e GUATTARI, 1984), seja através de certas abordagens no interior da teoria queer [homossexual] (HAVER, 1997). Sem dúvida, como em particular Laclau argumentaria de forma incisiva, somente se concebermos o futuro como genuinamente aberto podemos seriamente aceitar ou engajar-nos em uma noção genuína de política.

Agora, novamente - como no caso da primeira proposição - existe um paralelo com o modo pelo qual eu estou propondo que conceitualizemos a espacialidade. Tanto o espaço quanto a história são "abertos" - sem dúvida, à medida que a argumentação avança, espero que se torne evidente que estas duas aberturas são efetivamente dois lados da mesma moeda, essenciais um para o outro. ${ }^{6}$ Em outras palavras, conceitualizando o espaço como "aberto, não finalizado, sempre em devir", ou seja, como um pré-requisito essencial para a história ser aberta e, assim, após os argumentos de Laclau, um pré-requisito para a possibilidade da política.

$$
* * *
$$

É possível que, numa primeira leitura, essas proposições sobre espaço/espacialidade pareçam triviais, razoáveis e que sejam muito rapidamente aceitas. De uma forma estranha (embora, é claro, eu deseje sinceramente que vocês - eventualmente - concordem comigo), esta pode ser para mim uma resposta desapontadora. Isto porque também quero defender que estes elementos de uma imaginação revista do espaço são novos, que em alguns casos eles contradizem incisivamente e em outros casos desafiam seriamente as formas habituais com que pensamos o espaço. Um destes aspectos, como já foi mencionado, é que freqüentemente não pensamos sobre o espaço - nós usamos a palavra, no discurso popular ou acadêmico, sem termos plena consciência do que ela significa para nós ${ }^{7}$. Um outro aspecto do modo pelo qual esta revisão proposta para nossa imaginação do espaço se torna um desafio deriva do fato de que existem muitas conceitualizações que são surpreendentemente diferentes.

Assim, nesta parte do trabalho, com o objetivo de destacar o que é diferente nas três proposições acima elencadas, devo dedicar algum tempo para examinar algumas formas pelas quais o espaço tem sido pensado por teóricos e escolas de pensa-

\footnotetext{
6. Existe aqui uma ligação novamente com a primeira proposição. Para muitos anti-essencialistas, a verdadeira importância da sua posição (aquela de desafiar a natureza essencial - no sentido de imutável - das identidades) é de que, precisamente, ela mantém aberta a possibilidade de mudança. Como já foi sugerido, entretanto, e como irá aparecer ainda mais explicitamente mais adiante, a construção relacional efetivamente só garante a possibilidade de mudança quando a noção de "relações" não está confinada àquela de um sistema fechado.

7. Esta natureza não investigada da mobilização do conceito de espaço é, naturalmente, algo que Henri Lefebvre focaliza nos argumentos de abertura de "A produçăo do espaço". (LEFEBVRE, 1991)
} 
mento importantes, que são completamente distintas do que está sendo proposto aqui. Esta elaboração de outras formas de pensamento permitirá um aprofundamento do argumento aqui apresentado.

Primeiro, há uma longa e influente linha de pensamento na "Filosofia Continental" cuja principal preocupação era de fato, neste aspecto, a conceitualização do tempo, mas em cujo trabalho esta preocupação com o temporal tinha como subproduto um entendimento muito particular de espaço. (Esta conexão entre conceitualizações de tempo e conceitualizações de espaço não está restrita a este grupo. Como veremos, é parte integral de muitas das posições que se seguem. Faz parte, também, do meu próprio argumento, que as duas conceitualizações estão [coerente ou incoerentemente] relacionadas. No presente caso, como já foi indicado, o argumento é que qualquer conceitualização de tempo que seja radicalmente aberta requer como sua parceira uma conceitualização também aberta do espaço). Nesta primeira linha de pensamento provavelmente a figura emblemática é Henri Bergson $^{8}$. Sua influência permanece poderosa, hoje, talvez mais especialmente através do trabalho de Deleuze e Guattari. Assim, esta não é "simplesmente" uma questão histórica.

A segunda proposição deste artigo é a de que o espaço é a esfera da possibilidade da existência da multiplicidade. Por extensão, o espaço como uma dimensão é necessário para a existência da diferença. Isto é diametralmente oposto a Bergson. Para Bergson, é o tempo que é a dimensão essencial da diferença. A razão para isto é que, para Bergson e outros, incluindo muitos teóricos contemporâneos, "diferença" foi ela própria imaginada, não como um aspecto potencial da multiplicidade, como neste artigo, mas como mudança no tempo. Não devemos nos deter aqui nas razões que explicam a posição de Bergson, embora meu pressentimento pessoal seja de que elas derivam da batalha na qual esta corrente filosófica se engajou com a ciência newtoniana e einsteiniana (v. MASSEY, s/d). No que tange às conceitualizações do espaço, a lógica foi devastadora. Se a diferença é definida como mudança (de uma coisa no tempo, mais do que como a existência simultânea de uma multiplicidade de coisas), então o tempo é a dimensão crucial da diferença $e$ o tempo se torna a dimensão crucial, o único veículo, da criatividade. O espaço, por isso, é excluído de qualquer processo de criatividade (em outras palavras, a abertura do futuro, proposição três). Indiscutivelmente para Bergson o espaço era a dimensão da representação, da fixidez, do prender as coisas. Era muito mais a linguagem dos cientistas do que a vida do mundo (Bergson opunha uma à outra). Foi assim que ele pode escrever: "Devemos livrar-nos da espacialização imposta pela mente de modo a resgatar o contato com o âmago do verdadeiro viver, que subsiste somente na dimensão do tempo".

8. Ver em particular seus trabalhos "Time and free will" e "Matter and Memory". 
O espaço, então, como o reino da estase. Talvez a afirmação mais provocativa de Bergson a este respeito seja esta:

Qual é o papel do tempo? ... O tempo impede que tudo seja dado imediatamente... Não é ele o veículo da criatividade e da escolha? Não é a existência do tempo a prova da indeterminação da natureza?

Inúmeros pontos clamam por atenção aqui. Para começar, devemos salientar que "indeterminação", nesta citação, significa precisamente aquela criatividade e aquela possibilidade da política - aquela abertura genuína do futuro (proposição três!) tese que este artigo também está defendendo. Para Bergson, a mudança implicava verdadeira novidade, a produção do novo, de coisas ainda não totalmente determinadas pelo atual arranjo de forças. Assim, "para [Bergson] o futuro está em devir de um modo que nunca pode ser um mero rearranjo daquilo que já existia antes". (ADAM, 1990:24)

O primeiro ponto a observar, assim, é que existe aqui uma coincidência de aspirações. Tanto o projeto de Bergson quanto o argumento do presente artigo nos impelem a ampliar nossa conceitualização de temporalidade e de futuro.

O segundo ponto, entretanto, realça as divergências, e estas se referem ao nosso entendimento do que está sendo requerido do tempo e do espaço. Na primeira citação, Bergson escreve que o tempo é o veículo da mudança. Isto precisa evidentemente ser reconhecido. Mas ser o veículo não é o mesmo que ser a causa. A não ser que defendamos uma posição totalmente essencialista, o tempo não pode, de qualquer maneira, existir por si mesmo, sem apoio. Isto é, a menos que se recorra a uma noção de um desdobramento imanente de uma entidade indiferenciada, somente a interação pode produzir mudança (criatividade) e, portanto, tempo. Contudo, a possibilidade da interação depende da existência prévia da multiplicidade (deve existir mais de uma entidade a fim de que a interação seja possível; a forma simples do argumento é, certamente, que a própria interação é parte integrante da produção das entidades). Em outras palavras:

- para existir tempo deve existir interação;

- para existir interação deve existir multiplicidade:

- para existir multiplicidade deve existir espaço.

Em outras palavras e para modificar a citação de Bergson, o tempo pode sem dúvida "impedir que tudo seja dado imediatamente" (embora esta seja uma forma incrivelmente curiosa de propô-lo!), mas para existir tempo, pelo menos mais de uma coisa deve ser dada imediatamente. Para existir tempo, deve existir espaço.

Segundo, a escola do estruturalismo francês também trabalhou com uma conceitualização de espaço que está totalmente em desacordo com aquela que propomos aqui, e mais uma vez sua influência pode ainda ser fortemente detectada nos escritos de seus descendentes teóricos - por exemplo, Ernesto Laclau e Michel de Certeau, entre outros, incluindo Michel Foucault. Mais uma vez, como no caso de 
Bergson, os estímulos iniciais para a abordagem dos estruturalistas são estímulos com os quais este artigo tem considerável simpatia, e mais uma vez eles efetivamente se referiram - de forma central - ao tempo. Na Antropologia, em particular, um ímpeto na direção de uma conceitualização "estruturalista" do mundo derivou de uma atenção às implicações das então hegemônicas noções de narrativa temporal. Com muita freqüência, argumentavam eles, tais formas narrativas (temporais) de conceitualização do mundo conduziam a classificações de níveis de desenvolvimento que relegavam as sociedades que eles estudavam ao status de "primitivas", como se existissem somente enquanto precursores de nosso próprio status "desenvolvido". O estruturalismo defendia a coerência de tais sociedades em si mesmas. No lugar da dominância da narrativa temporal eles estabeleceram a significância de estruturas auto-sustentadas internamente coerentes. Até aí tudo bem.

Os problemas surgiram quando este debate foi traduzido (mal traduzido, eu diria) em conceitualizações de (e dicotomias entre) espaço e tempo. Os estruturalistas argumentavam contra a dominância da temporalidade (na verdade, contra uma visão particular de temporalidade). Na avidez de assim procederem e num salto de lógica que pode ser compreensível mas que não tem absolutamente fundamentação filosófica, equipararam suas estruturas a-temporais com a espacialidade. O pressuposto subentendido era o de que tempo e espaço eram opostos um ao outro, e que o espaço representava uma falta de temporalidade. Tal como em Bergson, assim, os estruturalistas estabeleceram tempo e espaço em oposição um ao outro (Bergson defendendo o tempo, os estruturalistas o espaço) e, tal como em Bergson, o espacial era entendido como a esfera da estase e da fixidez.

Mesmo no projeto dos estruturalistas, não havia necessidade disso tudo ter ocorrido, pois as estruturas que eles propunham, embora pudessem ser deficientes em temporalidade, não eram de modo algum espaciais. Eram simplesmente a-temporais (OSBORNE, 1995). Elas só seriam chamadas de espaciais por causa de um pressuposto fraco de que deficiência de tempo deve significar que estamos tratando de espaço.

Esta visão da espacialidade como estase, entretanto, foi reforçada pela sua conceitualização das próprias estruturas. Eles as imaginavam como sistemas totalmente conectados de relações. "Espaço", então, era entendido não apenas como uma sincronia mas como uma sincronia fechada, e oposta à diacronia. Certamente, assim, esta noção de espacialidade está de acordo com a primeira proposição deste artigo: de que o espaço é um produto de inter-relações. Mas ela está em total contradição com a terceira proposição: de que o espaço está sempre num processo de devir, que ele nunca é um sistema fechado. Foi esta estase de suas estruturas/espaço que conduziu a todas as reconhecidas dificuldades em mobilizar estas estruturas e às oposições intransponíveis entre pares tais como "langue" e "parole". Tal como escreve De Certeau: "(...) a espacialização do discurso científico, (...) a escrita científica reduz constantemente o tempo, este elemento fugitivo, à normalidade de um sistema legível e observável". (DE CERTEAU, 1984:89). Assim, não é de sur- 
preender que Foucault possa refletir retrospectivamente a respeito de como costumávamos pensar o espaço como o morto, o fixo, o imóvel.

Terceiro, há um artifício mais familiar, encontrado nas Ciências Sociais (inclusive na Geografia) e num amplo espectro de discursos populares correntes. Trata-se da estratégia que foi denominada, em trabalho anterior, "conceber o espaço em termos temporais".

Quando utilizamos termos como "avançado", "atrasado", "em desenvolvimento", "moderno", referindo-nos a diferentes regiões do planeta, o que acontece é que diferenças espaciais estão sendo imaginadas como sendo temporais. Diferenças geográficas estão sendo reconcebidas em termos de sequiência histórica. É um artifício que desenvolve interessantes relações com duas outras posições aqui apresentadas. Em certo sentido está-se adotando uma posição bergsoniana, a de que a diferença é essencialmente temporal. Por outro lado, este é o tipo de leitura da espacialidade em relação à qual poderíamos imaginar a objeção dos estruturalistas.

Esta concepção de espaço em termos temporais é um modo de conceber a diferença que é típico de muitas das grandes leituras modernistas do mundo. As estórias de progresso (da tradição à modernidade), de desenvolvimento, de modernização, a fábula marxista da evolução através dos modos de produção (feudal, capitalista, socialista, comunista), muitas das nossas estórias atuais sobre a "globalização" (MASSEY, 1999) ...todas elas compartilham de uma imaginação geográfica que re-arranja as diferenças espaciais em termos de sequência temporal. A implicação disso é que lugares não são genuinamente diferentes; na realidade, eles simplesmente estão à frente ou atrás numa mesma estória: suas "diferenças" consistem apenas no lugar que eles ocupam na fila da história.

Este não é em si mesmo um argumento original deste trabalho. Foucault de certa forma reconhecia isto, e há um forte debate em termos semelhantes na Antropologia (v. FABIAN, 1983). Mas o que realmente nunca foi destacado foi que esta manobra reprime a real significância da espacialidade. Ela oblitera, ou pelo menos reduz, a real importância e a verdadeira medida das diferenças em questão. $\mathrm{O}$ argumento aqui, neste trabalho, é o de que um verdadeiro reconhecimento "político" da diferença deve entendê-la como algo mais do que um lugar numa sequiência; de que um reconhecimento mais completo da diferença deveria reconhecer a contemporaneidade da diferença, reconhecer que os "outros" realmente existentes podem não estar apenas nos seguindo, mas ter suas próprias estórias para contar. Neste sentido, seria concedido ao outro, ao diferente, pelo menos um determinado grau de autonomia. Seria concedida pelo menos a possibilidade de trajetórias relativamente autônomas. Em outras palavras, isto levaria em consideração a possibilidade da co-existência de uma multiplicidade de histórias.

Entretanto - e para trazer de volta o argumento mais uma vez - para que haja histórias múltiplas, co-existentes, deve existir espaço. Em outras palavras: o pleno entendimento da espacialidade envolve o reconhecimento de que há mais de uma estória se passando no mundo e que essas estórias têm, pelo menos, uma relativa autonomia. 
Quarto, há uma abordagem final para entender o espaço da qual é preciso livrarse. Pois, como parte e parcela daquela visão "modernista" do espaço como espaço temporalizado, existe algo mais: um modo particular de entender a relação entre "espaço" e "sociedade". Acima de tudo, o espaço geográfico foi imaginado como parcelado, dividido em localidades, lugares, regiões... Como Gupta e Ferguson escreveram: "Representações do espaço nas ciências sociais são marcadamente dependentes de imagens de quebra, ruptura e disjunção". (GUPTA e FERGUSON, 1992:6). Além disso, este espaço fragmentado foi imàginado em relação a uma forma particular de organização da sociedade: em Estados nações, comunidades locais, tribos locais dos antropólogos, culturas regionais dos sociólogos e geógrafos. Havia, em outras palavras, um pressuposto de um isomorfismo entre cultura/sociedade, por um lado, e lugar, por outro. Culturas tinham seus próprios lugares.

Havia, além disso, mais um passo, pois as diferenças entre essas culturas localmente situadas e as suas identidades eram tomadas como tendo sido internamente geradas e pré-constituidas. Primeiro, imaginava-se, as culturas (culturas regionais, nações etc.) surgiam e assim entravam em interação. As características de um lugar e sua "cultura local" de algum modo eram concebidas como tendo brotado do próprio solo. Trata-se de uma clássica visão newtoniana, como se fossem bolas de bilhar, de lugares e regiões e da constituição de identidades e da diferença, fundamentalmente essencialista e individualista. E é sem dúvida um modo de entendimento que pode, ele próprio, ser objeto de análise. Como Walker propõe:

Teorias de relações internacionais são mais interessantes como aspectos da política do mundo contemporâneo que precisam ser explicadas do que como explicações da política do mundo contemporâneo... elas podem ser descritas como um discurso característico do Estado moderno e como uma prática constitutiva. (WALKER, 1993:6)

Neste artigo, em contraste com a visão fragmentada do espaço, há uma imaginação do espaço e dos lugares, e da identidade dos lugares, regiões, nações..., em parte, precisamente, como um produto de interações. Além disso, este argumento é colocado tanto como princípio (como um modo útil de conceitualizar o espaço) quanto como uma questão de entendimento histórico. Isto é, trata-se tanto de uma proposição teórica de como podemos imaginar melhor lugares e regiões (v. ALLEN et al., 1998) quanto um argumento de que as coisas sempre foram desta forma.

Não é o caso, por exemplo, que lugares e nações teriam existido num estado de auto-enclausuramento até que a atual fase da globalização derrubasse suas fronteiras previamente soberanas. Eric Wolf, no seu livro "Europe and the people without history" (WOLF, 1982), sustentou convincentemente que, para as sociedades pré1492, nunca houve "isolamentos culturais". Mesmo os ícones mais consagrados do caráter fundamental dos lugares têm "rotas" geográficas que são muito mais amplas do que a área geográfica que eles pretendem ocupar - a icônica agulha da 
torre da igreja Anglicana saúda uma religião nascida na "Margem Ocidental" da Palestina; a "verdadeira" xícara de chá inglesa dependeu, para o seu aparecimento, de um colonialismo que se estendia da escravidão do açúcar no Caribe à Companhia das Índias Orientais e às guerras do ópio na China. Assim, a partir deste modo de olhar as coisas, somos introduzidos a uma questão atual: como devemos caracterizar a identidade da nova "Europa"? Será que podemos imaginála de forma a reconhecer que a "europeidade" se deve aos longos séculos de relações com um mundo mais amplo ao seu redor?

Uma breve recapitulação deve ser feita. O argumento é que, para a conceitualização de espaço/espacialidade, é crucial o reconhecimento de sua relação essencial com e de sua constituição através da coexistência da(s) diferença(s) - a multiplicidade, sua habilidade em incorporar a coexistência de trajetórias relativamente independentes. Trata-se de uma proposta para reconhecer o espaço como a esfera do encontro, ou não, dessas trajetórias - onde elas coexistem, afetam uma a outra, lutam. O espaço, então, é o produto das dificuldades e complexidades, dos entrelaçamentos e dos não-entrelaçamentos de relações, desde o inimaginavelmente cósmico até o intimamente pequeno. O espaço, para repetir mais uma vez, é o produto de inter-relações.

Ademais, como um resultado disso, e como já foi aqui proposto, o espaço encontra-se sempre em processo, num fazer-se, nunca está acabado. Existem sempre extremidades inacabadas (loose ends) no espaço.

Tudo isso leva agora a uma conclusão adicional. Este caráter relacional do espaço, juntamente com sua abertura, significa que o espaço também contém, sempre, um grau de inesperado, de imprevisível. Assim, tal como extremidades inacabadas (loose ends), o espaço sempre contém, também, um elemento de "caos" (do ainda ñão prescrito pelo sistema). É um "caos" que resulta daquelas justaposições imprevisíveis, daquelas separações acidentais, o caráter freqüentemente paradoxal das configurações geográficas em que, precisamente, um número de trajetórias distintas se entrelaçam e, algumas vezes, interagem. O espaço, em outras palavras, é inerentemente "disruptivo" (MASSEY, 1997). Talvez de forma a mais surpreendente, dadas as conceitualizações hegemônicas, o espaço não é uma superfície.

Agora, a razão desta recapitulação é permitir que eu acrescente dois pontos.

O primeiro consiste simplesmente em enfatizar que este caráter disruptivo do espaço é importante. Ele permite distinguir o argumento defendido aqui sobre a inter-relacionalidade (interrelationality) daquilo que caracteriza a posição do que se pode chamar de "holismo New Age". Este vê o mundo como uma construção através de inter-relações, mas onde, em certo sentido, todas as relações já se encontram previamente estabelecidas: onde tudo já está conectado com tudo. Nestá formulação há o perigo de se alcançar um fechamento totalizante, a claustrofobia 
do sistema fechado, a coerência fechada onde não existe nenhuma abertura para o novo. Afastarmo-nos da visão "individualista" do espaço criticada antes (o espaço como container para "coisas") para este tipo de racionalidade, é mover-se diretamente de um mundo em forma de bolas de bilhar de um newtonianismo essencialista para um holismo fechado que não deixa abertura para uma política ativa.

Dessa forma, este artigo não está defendendo essa mudança. Está defendendo sobretudo um "sistema" (apesar do próprio termo não șer muito apropriado) aberto, que contém relações existentes, mutáveis e futuras. Trata-se da formação de potencial. Contém, como um aspecto integrante, o que tem sido denominado "a produtividade (productiveness) da incoerência". (LEVIN, 1989)

Mais ainda, essa produtividade (productiveness) da incoerência torna-se chave para o segundo ponto: um ponto que sem dúvida pode ser suficientemente significativo para garantir o status de uma "quarta proposição". Este ponto é que, precisamente porque ela é a esfera da justaposição potencial de diferentes narrativas, do potencial forjar de novas relações, a espacialidade é também uma fonte de produção de novas trajetórias, de novas estórias. É uma fonte de produção de novos espaços, de novas identidades, novas relações e diferenças (é interessante e significativo como o argumento neste ponto é limitado pela indisponibilidade de uma linguagem adequada). Retornando às reflexões anteriores sobre Bergson (e novamente num debate com ele), a implicação é que o tempo necessita do espaço para ele próprio continuar existindo. Tempo e espaço nasceram juntos. Torna-se realmente imperativo que conceitualizemos o mundo em termos de tempo-espaço.

Nas décadas recentes muitos geógrafos têm defendido a re-priorização do espacial. Talvez o que é ainda mais importante é o fim da separação radical entre espaço e tempo, que nas Ciências Sociais se deixou praticamente inquestionado desde pelo menos os pronunciamentos de Kant.

Há, entretanto, uma questão que precisa agora ser levantada e destacada. Ainda que tudo o que comentamos acima seja francamente aceito, ainda resta a questão de porque nós devemos imaginar o espaço dessa forma. Há uma resposta possível que é cada vez mais popular, hoje, mas em relação à qual eu permaneço no mínimo cautelosa, se não inteiramente não convencida. Trata-se do argumento: "A Física assim nos explica" Um dos aspectos mais divertidos e intrigantes de muitos dos escritos correntes sob o signo do pós-modernismo é o de que, por um lado, há uma profunda suspeita em relação a toda forma de reivindicação a verdades universais e, por outro, há um recurso liberal (e, eu diria, frequientemente cômodo) a referências das Ciências Naturais. Mecânica quântica, teoria do caos, fratais... são freqüentemente chamadas a ter uma (muitas vezes não especificada) função em argumentos que, em si mesmos, encontram-se centralmente ligados ao mundo humano. Até que tenhamos um debate mais sério sobre o status desses vínculos, eles precisam ser tratados, 
no mínimo, com muito cuidado. Os próprios físicos argumentam entre eles da mesma forma. Não está claro porque as assim chamadas ciências "duras" devem ser tratadas como uma fonte de verdade inexpugnável por aqueles que trabalham no campo comumente denominado "social". (MASSEY, s/d, mimeo.) Assim, apesar de minhas referências anteriores ao newtonianismo, não é este o domínio ao qual eu pretendo me referir para justificar as proposições deste artigo.

Esse tipo de invocação da "Física" evidencia, naturalmente, uma necessidade de recorrer a uma noção de verdade objetiva, absoluta. Não é este o tipo de estratégia que pretendo empregar aqui. Nesta abordagem sobre a conceitualização de espaço prefiro sustentar um fundamento bastante distinto: o de que entendimentos particulares (de espaço, por exemplo) tornam-se apropriados em momentos específicos do espaço-tempo e a partir de perspectivas (políticas) particulares. Antigas formas de pensamento podem cair por terra, podem se tornar bloqueios ao pensamento e à ação, podem sem dúvida ser mobilizadas ativamente como bloqueios à mudança. Sob estas bases, a razão para sugerir este modo particular de conceitualização do espaço não é a de uma reivindicação para sua verdade ou precisão eterna ou objetiva. Antes, fundamenta-se na recusa a ciladas reacionárias de formulações previamente hegemônicas e abre terreno para novas questões que - politicamente - eu diria, precisam urgentemente ser colocadas. Assim, a seção final deste texto segue quatro modos nos quais acredito que estes argumentos se revelam: como o mundo que nós estamos visualizando ao nos aproximarmos do novo milênio nos demanda novas imaginações geográficas.

O primeiro desses modos é bastante geral e pode ser muito resumidamente expresso. Refere-se simplesmente ao fato de que esta abordagem abre o espaço/a espacialidade para a política de uma forma nova. Sem dúvida isto possibilita que ele se torne parte integral do político. O espaço não é mais o domínio do que está morto (Bergson, os estruturalistas), nem simplesmente um corte horizontal através do tempo, nem uma dimensão cuja especificidade fica persistentemente oclusa ao ser lida em termos de temporalidade (muitas das versões correntes sobre "globalização"). Mais apropriadamente, o espaço se expressa agora como parte (e uma parte necessária) da geração e da produção do novo. Em outras palavras, a questão aqui não é a ênfase somente na produção do espaço, mas o próprio espaço como integrante na produção da sociedade. Indubitavelmente, o argumento é que se nós queremos que o tempo (o futuro) seja aberto (como Bergson fez e como muitos agora estão afirmando) então precisamos conceitualizar o espaço desta forma, isto é, como um espaço inteiramente aberto e ativo.

A segunda razão para defender essa forma de pensamento sobre o espaço é mais específica e diz respeito à questão particular da conceitualização do espaço em termos de relações. Existem, creio eu, inúmeros caminhos para sustentar a relevância desta abordagem, muitos deles propostos nos últimos anos pelos que se dedicam aos estudos queer [homossexuais], feministas e pós-coloniais. Mais do que repetir seus argumentos, devo considerar uma questão mais particular à Geografia: a ques- 
tão da identidade, neste caso, particularmente, a questão da identidade do lugar ${ }^{9}$. Neste contexto, "lugar" pode se referir a localidade, região, Estado-nação, uma entidade recém-criada como a "União Européia" ou qualquer outra entidade geográfica. Tais "objetos" têm sido sempre centrais ao pensamento geográfico e há muitos debates sobre a melhor forma de defini-los (embora eu deva reconhecer que muito deste debate esteve ligado mais à definição técnica do que à conceitualização: frequientemente assumiu-se que a incumbência era a de desenhar uma linha em torno de um espaço e que o problema era simplesmente o de onde deveríamos desenhá-la).

Para mim, pessoalmente, os dramáticos eventos de 1989 trouxeram à tona um número de questões que há tempos estavam me incomodando. Aquele ano viu a emergência, através da Eurásia, do apogeu de uma série de novos nacionalismos, de paroquialismos locais, de mútuas antipatias entre etnicidades que com frequiência definiam-se a si mesmas em termos geográficos (e por isso reivindicavam uma base geográfica). Foi a partir deste período que termos como "limpeza étnica" começaram outra vez a se fazer presentes em nosso continente. Houve violência sangrenta na defesa de especificidades locais (o que continua hoje, em muitas partes do mundo). Para mim isto gerou um conflito interno. Por um lado, eu absolutamente rejeitava as reivindicações por exclusividade local e os termos pelos quais elas estavam sendo feitas. Por outro lado, eu absolutamente não queria deixar de lado a capacidade de apreciar a diferença local (uma das razões pelas quais eu me tornei, e permaneço, geógrafa).

Minha resposta era a de começar a tentar re-imaginar o lugar (ou, de forma mais geral, a especificidade geográfica) de um modo que fosse: (i) não delimitado, (ii) não definido em termos de exclusividade, (iii) não definido em termos de contraposição entre um dentro [inside] e um fora [outside] e (iv) não dependente de falsas noções de uma autenticidade internamente gerada. Isto significa precisamente, em outras palavras, rejeitar aquela conceitualização em termos de essencialismo newtoniano, mencionada anteriormente. Esta forma de conceitualizar a espacialidade havia se tornado um bloqueio para pensar nossa forma de superação do confronto dos essencialismos geográficos. Ao invés disso, significou começar a defender um entendimento da identidade do lugar como sendo construída através de relações com outras partes: "um sentido global de lugar" (MASSEY, 1994). É este tipo de abordagem, eu acredito, que pode possibilitar-nos defender uma posição política que permita tanto a apreciação das especificidades locais quanto a firme manutenção de uma perspectiva internacionalista.

Em terceiro lugar, conceituar "identidade" deste modo - tanto a identidade em geral quanto, mais particularmente, a especificidade geográfica - permite suscitar

9. Este argumento foi desenvolvido mais amplamente em Massey, 1998, onde também é explorada a relação entre a conceitualização de diferentes tipos de identidade (gênero, lugar, etnia, etc.). 
novas questões e novos argumentos sobre as formas da política possível. Como sugerido anteriormente, creio que nossa época exige o que pode ser chamado de "uma política relacional". Quer dizer, não uma política de identidades pré-concebidas (nem uma "política de identidade" como nos Estados Unidos), mas uma política de exposição dos mapas de poder através dos quais as identidades são construídas. Há, naturalmente, uma política real (e, creio eu, reacionária) que está subordinada justamente à supressão do reconhecimento das cartografias de poder sobre as quais, necessariamente, está baseada a construção da identidade: tão simples reconhecimento significa dar um passo à frente. O simples reconhecimento sozinho, entretanto, não é suficiente. Como defendido anteriormente, a proposição de que "estamos todos inter-relacionados" é insuficiente. Pois todas aquelas relações são ativamente construídas (e algumas delas podem nunca ser construídas) e o fato de que elas são construídas (elas são integralmente práticas sociais), por sua vez, implica que estão repletas de poder social. Assim, politicamente, o que devemos fazer é reconhecer também a forma dessas relações, seu inevitável conteúdo de poder social, as relações de dominância e subordinação que elas podem requerer ou (mais positivamente), o potencial de capacidades que elas podem produzir.

Tal política deveria, em outra palavras, mais do que reivindicar direitos para um conjunto rapidamente multiplicador de identidades pré-constituídas, ser responsável por e - quando apropriado - desafiar a forma de relações através das quais aquelas identidades são formadas - e nas quais, sem dúvida, estamos individual e coletivamente posicionados e através das quais a sociedade, em geral, é constituída.

Em quarto lugar, e finalmente, isso por sua vez conecta-se com uma forma adicional pela qual podemos pensar sobre política. Já foi proposto que muitas abordagens "modernistas" da política (tanto liberal-progressistas quanto marxistas) imaginam o mundo em termos de sequiências históricas. Isto tem dois efeitos altamente significativos. Por um lado, significa que o futuro, em princípio, já é conhecido, e suas linhas gerais já esboçadas nos termos da grande narrativa. Havia, é claro, uma persistente ambigüidade neste sentido, pois continuávamos a tomar ações políticas mesmo "conhecendo" o que o futuro estava prenunciando (foi uma dessas ambiguiidades que provocou o que veio a ser conhecido como "o debate da estrutua/ação", e que também fazia parte dos fundamentos dos problemas dualistas do estruturalismo). O que agora está (deve estar?) na agenda é uma apreciação mais completa do fato de que o futuro é genuinamente aberto. Por outro lado, aquela organização modernista do mundo em torno de uma simples grande narrativa suprimia a existência da diferença real. Se existe somente uma narrativa, um único futuro em direção ao qual estamos caminhando (na forma com que imaginamos o mundo), então teríamos suprimido as genuínas e potenciais multiplicidades do jespacial. A simples história linear organiza o espaço em uma seqüência temporal. Uma recusa a temporalizar o espaço, portanto, abre nossas estórias para a multiplicidade, ao mesmo tempo em que reconhece que o futuro não está escrito previamente, isto é, que o futuro, pelo menos em certa medida, e considerados os cons- 
trangimentos das circunstâncias, não é produto de nossa própria escolha, mas que nós próprios o fazemos.

\section{FILOSOFIA E POLÍTICA DA ESPACIALIDADE: ALGUMAS CONSIDERAÇÕES}

Resumo: A principal preocupação deste artigo é com o modo como podemos pensar o espaço/a espacialidade (e a política que isto implica) considerando-o como um produto de interrelações, como a esfera de possibilidade da existência da multiplicidade e como algo nunca terminado, sempre em construção.

Palavras-chave: Espaço, Filosofia, Política da Espacialidade

\section{PHILOSOPHY AND POLITICS OF SPATIALITY: SOME CONSIDERATIONS}

Abstract: The main concern in this paper is with how we might think about space/spatiality (and the politics it implies) considering space as a product of interrelations, the sphere of the possibility of the existence of multiplicity and as never finished, always being made.

Keywords: Space, Philosophy, Politics of Spatiality.

\section{BIBLIOGRAFIA}

ADAM, B. 1990. Time and social theory. Oxford: Polity Press.

ALLEN, J.; MASSEY, D. e COCHRANE, A. 1998. Rethinking the region. Londres: Routledge.

DELEUZE, G. e GUATTARI, F. 1984. A thousand plateaus: capitalism and schizophrenia. Londres: The Athlone Press.

FABIAN, J. 1983. Time and the other: how Anthropology makes its object. Nova York: Columbia University Press.

GROSSBERG, L. 1996. The space of culture, the power of space. In: Chambers, I. e Curti, L. (eds.) The postcolonial question: common skies, divided horizons. Londres: Routledge.

GUPTA, A. e FERGUSON, J. 1992. Beyond "culture": space, identity and the politics of difference. Cultural Anthropology 7.

HAVER, W. 1997. Queer research, or, how to practise invention to the brink of intelligibility. In: Golding, S. (org.) The eight technologies of otherness. Londres: Routledge.

LACLAU, E. 1990. New reflections on the revolution of our time. Londres: Verso. LEFEBVRE, H. 1991. The Production of Space. Oxford: Blackwell.

LEVIN, Y. 1989. Dismanding the spectacle: the cinema of Guy Débord. In: Sussmann, E. (org.) On the passage of a few people through a rather brief moment in time: Situationist International 1957-1972. Cambridge (Mass.): MIT Press.

MASSEY, D. 1991. A global sense of place. Marxism Today Junho 1991 (reimpresso em Massey, D. 1994. Space, Place and Gender. Oxford: Polity Press) 
1995. Thinking radical democracy spatially. Environment and Planning D: Society \& Space 13.

1997. Spatial disruptions. In: Golding, S., (org.) The eight technologies of otherness. Londres: Routledge.

1998. "Identity": some parallels between feminist debate and the identity of place. Berichte zur Deutschen Landeskunde 72.

1999. Imagining globalisation: power-genmetries of space-time. In: Brah, A., Hickman, M. e Mac an Ghaill, M. (orgs.) Future worlds: migration, environment and globalization: Basingstoke: Macmillan.

1999. Spaces of politics. In: Massey, D.; Allen, J. e Sarre, P. (orgs.) 1999. Human Geography today. Oxford: Polity Press.

s/d. Physical Geography/Human Geography: thinking about space-time. (mimeo.)

OSBORNE, P. 1995. The politics of time: modernity and avant-garde. Londres: Verso.

WALKER, R. 1993. Insideloutside: international relations as political theory. Cambridge: Cambridge University Press.

WOLF, E. 1982. Europe and the people without history. Londres: University of California Press. 